\title{
The Platonic-Freudian Model of Mind: Defining "Self" and "Other" as Psychoinformatic Primitives
}

\author{
Suraj Sood ${ }^{1}$ \\ ${ }^{1}$ The Sirius Project \\ thesiriusproj@gmail.com
}

\begin{abstract}
As "nurtural" (rather than merely natural) kinds of human beings, people are complex and multifaceted. Any complete human science would require a complete theory of persons. Accomplishing the latter is the core objective of the present article.

First, a feature list first laid out in [1] is summarized. This list is briefly critiqued. Next, the concept of person engaged with is expanded with the addition of nine novel features. These features follow from "holarchic psychoinformatics" [2], which was first propounded as a step forward from Sood's analytic treatment of third-force, existential-humanistic psychology. Person is formalized as a function of self and other; they are also granted to be romantic, existential, humanistic, chemical, environmental, hedonic and eudaimonic (happiness-seeking), conservative, and liberal. These are in addition to persons being physical, biological, psychological, social, cultural, and spiritual. Sood's holarchic view of persons is enlarged.

Psychologically, augmented cognition as an established field of research and practice begets the formal studies of augmented affect, augmented behavior, and augmented motivation. All such interdisciplinary fields are required for the human-computer interactionist's study of augmented mind, more broadly.

Additionally, this article builds on the person-situation interaction framework formalized in [1]. It does so by adding a formalization following from the discussion of psychological situations put forward by Rauthmann, Sherman, and Funder in [3]. The formalization of psychological situations sets them as a function of cues, characteristics, and classes. Further psychological equations that follow from this article's formalisms of person and situation, when considered along with Sood's formulae for mind and behavior, are then presented.
\end{abstract}

Keywords: holarchy, person-situation interaction, third-force psychology, self, other

\section{$1 \quad$ Introduction}

In John Carpenter's 1974 movie Dark Star, Commander Powell instructs spaceship commanding officer Doolittle to teach a robotic bomb "a little phenomenology" [46]. Doolittle then engages in Socratic discourse with Bomb \#20, hoping to prevent it from fulfilling its singular task: to explode. The discourse includes a Cartesian meditation on proper skepticism toward the sensory data taken in by a given being. Based on this, Doolittle argues that Bomb \#20 cannot prove that its command to explode is working data; Bomb \#20 seems to accept this, but extends the logic to include Sergeant Pinback as being "false data". Since it would be illogical to act upon faulty data, Bomb \#20 tunes Pinback out in favor of fulfilling its purpose. Bomb \#20 detonates.

The interactions between Doolittle and Pinback with Bomb \#20 impart an important lesson for human-computer interaction (HCI). Specifically: we must communicate logically with robots, or else they might act against their human creators' best wishes. Thus, it behooves HCI and the augmented cognition community to understand humans, computers (e.g., robots), and how they interact in order to augment their collective, cognitive phenomenology.

In this article, a framework of persons presented in [1] is critiqued and subsequently expanded. Following this, the concept of person engaged with is expanded with the addition of nine novel features. These features follow from Sood's [2] "holarchic psychoinformatics", which was first propounded as a step forward from his analytic treatment of third-force, existentialhumanistic psychology. Person is formalized as a function of self and other; they are further granted to be romantic, existential, humanistic, chemical, environmental, hedonic and eudaimonic (happiness-seeking), conservative, and liberal. These are in addition to persons being physical, chemical, biological, psychological, social, cultural, and spiritual (as explicated in Sood's [2] theory of reality). Put more simply: The holarchic view of persons is enlarged. 
Additionally, this article builds on the person-situation interaction framework formalized in Sood [1]. It does so by adding a formalization following from the discussion of psychological situations put forward by Rauthmann, Sherman, and Funder in [3]. The formalization of psychological situations sets them as a function of cues, characteristics, and classes. Further psychological equations that follow from this article's formalisms of person and situation, when considered along with Sood's formulae for mind and behavior, are presented. A series of novel concepts relevant to augmented cognition as a function of HCI are then propounded. In the last place, computational psychology is discussed in relation to theoretical psychology in the service of strengthening human-machine symbiosis.

\section{$2 \quad$ Related Work}

Sood [20] posited 18 human features in answering the question of what it means to be human (or, perhaps to be more specificpeople). Sood's features — with the additions of sub-features learning and attention within feature 18 - included

1. Physical - People's bodies are composed of matter. Further, people interact with other physical objects.

2. Biological - People breathe, eat, and drink; and a great many of them have sex and reproduce.

3. Temporal - People are born, they live, and they die; they experience time.

4. Cultural - People are embedded in cultures characterized by unique but shared ways of being.

5. Social - People participate in societies consisting of concrete relations between themselves and others.

6. Economic - People are agents who trade goods and services with one another in marketplaces.

7. Technological-People invent and utilize tools to perform tasks they were previously unable or less able to accomplish.

8. Artistic - People express themselves through the creation of original works such as paintings and songs.

9. Intellectual - People aim to comprehend reality and achieve accurate understandings of it.

10. Moral - People have unique and shared ideas of wrong versus right action.

11. Spiritual - People seek enlightenment, wisdom, and contact with the divine or supernatural via practices such as meditation and prayer.

12. Religious - People worship what they deem as sacred (e.g., God or Gods) through rituals and organized communion.

13. Political - People negotiate and have interests that are in line or at odds with those of others.

14. Athletic - Whether for fitness or organized play, people exercise their bodies and minds.

15. Professional - People work toward particular goals, including earning money and achieving satisfaction.

16. Recreational - People enjoy leisurely activities such as taking walks and attending parties.

17. Linguistic - People communicate via representational symbol systems characterized by semantics, syntax, and pragmatics.

18. Psychological - People have minds and engage in behaviors. More specifically, they think, feel, have personalities, interact with situations, are motivated, sense, perceive, experience, learn, and pay attention.

The above list may be considered more relevant to personology than personality psychology. McCrae and Costa [22] discussed "personologists" (p. 81) but did not distinguish such researchers from personality psychologists. Such a distinction should be worked out for technical reasons: primarily, that of precision. Modern personality psychology is defined as involving: 1) "an emphasis on defining and understanding individual differences"; and 2) "an emphasis on the ways in which the various parts of the person are organized" ([23], p. 100). Kukla [47] states that the personality theorist's task is to put together the pieces of human nature independently constructed by psychology's "process areas" (including social and perceptual psychologies) (p. vii). Personology is simply the study of persons.

Given list item 18 which states the core topics of psychological inquiry, one could most reasonably expect E-H psychologists to focus on the sum-total of its items. These psychologists need to include cognition, affect, personality, situationality, behavior, motivation, sensation, perception, experience, learning, and attention in their ultimate descriptions of who people are, their explanations of how people come to be, and their predictions of whom people are expected to become.

Within psychology, Freud was the pioneer of personality vis-à-vis mind as much as Skinner was the same for behavior [13]. Affect has been addressed by psychologists via the five factor model (FFM) constructs of Extraversion (positive emotion) and Neuroticism (negative emotion); cognition was included in Kelly's [28] personal construct and Dweck and Leggett's [29] socialcognitive theories. Experience, meaning, and motivation have been taken up by third force theorists such as Kelly, Maslow, and Rogers, in addition to positive psychologists (see, e.g., Proctor, Tweed, \& Morris [30]). Lastly, learning has been covered by Bandura \& Huston [51] and attention by philosophical, perceptual, and cognitive psychologists (e.g., William James).

Despite the progress summarized above, it remains an open question whether psychologists have fully accounted for both people and their situations. What determines their interaction? The best-established construct that is closest to the former is personality. Situations, on the other hand, have no corresponding construct denoting situationality. It may be partially inferred from this latter fact that psychologists understand personality better than situationality. Formalizing situation is undertaken later in this paper. First, however, Sood's multidimensional notion of person is expanded before being formalized in terms of more basic, 
psychological primitives. Such primitives have been introduced in this and previous works to address what has been called "the units of analysis problem in psychology" ([31], p. 177).

\section{Expanding the "Person" Concept}

\subsection{Romantic, Existential, Humanistic, Chemical, Environmental, Hedonic and Eudaimonic, Conservative, and Liberal Features}

The following nine features are now added to Sood's original list:

19. Romantic - People become emotionally involved with one another. Most get married.

20. Existential - People are responsible and free: they have "psychological wills"" ${ }^{2}$

21. Humanistic - People are creative, spontaneous, and active beings who contribute to the furthering of humanity.

22. Chemical-People are composed in part of physical reactions taking place throughout their bodies.

23. Environmental - People engage in a variety of ways with their surroundings.

24. Hedonic - People seek happiness in the form of pleasure.

25. Eudaimonic - People seek happiness in the form of fulfillment.

26. Conservative - People live in accordance with rules and principles designed with security in mind.

27. Liberal - People live freely to maximize (e.g.) diversity, inclusion, and peace.

19 is added since it is arguably not fully subsumable beneath 5 (social); nor, probably, within 9 (intellectual) (contra-cognitivist models that view affect as merely a class of cognition: see [10] for a treatment of this perspective). Despite this, marriage is an established social and religious (12) convention. Moreover, romantic being in the present sense is mostly meant as being affective (in the same sense as in 18: people "feel"). It could be expressed artistically (8), but is not reducible to such. 19 could thereby be viewed as a product of 5, 8,9,12, and 18, though it need not be necessarily. 26 and 27 are meant not merely in their political senses, but rather more broadly to encompass human being and doing.

People are also inherently humanistic and environmental. For the theoretical psychologist, the latter is to be sharply distinguished from persons' being situational as in 18. Varela et al. [11] propounded the original enactive framework marrying cognitive science with phenomenology, asserting that "the organism both initiates and is shaped by the environment" (p. 174). Sood [1] substituted "organism" and "environment" in this statement with "person" and "situation" respectively, asserting that doing so rendered his treatment more psychological (and so less biological). Lewin [12] formalized human behavior as

$$
B e=F[P, E]
$$

Where $B e$ equaled "behavior", $P$ equals "person", and $E$ equals "environment". Lewin's statement reads "Behavior = Function of person and environment" (p. 878). Sood's [2] formalization of human behavior was assigned the variable $B$, which equaled $F[S m, R p]$

$$
B=F[S m, R p]
$$

Where $S m$ equals "stimulus" and $R p$ equals "response". Sood revised Lewin's behavioral formula to align more with traditional behavioristic psychology—viz., Skinner's [13]—and truncated the latter's $B e$ variable to simply $B$.

$S m$ could be regarded as analogous, if not identical, with $E$ in that for behaviorists like Skinner, stimuli were objects in the subject's surrounding (external) environment. For Rauthmann et al. [3], situations are composed partially of environmental cues that are physical, objectively quantifiable stimuli. While this framing suggests that the environment should be conceived as being part of situationality, for the present discussion, the interchangeability of $E, S m$, and situationality (formalized later in this chapter) is simply to be regarded as noteworthy.

\subsection{The Person Equation}

Psychological persons may be said to be either selves or others. Psychological notions of self and other pervade the existential psychological literature [4; for Martin Buber's discussion of the related "I and thou" phenomenon, see 5]. Sood [1] formalized

\footnotetext{
${ }^{1}$ Various theories of psychological will have been proposed in the past two centuries, ranging from Friedrich Nietzsche's "will to power" to Viktor Frankl's "will to meaning". Will is used in the present context to refer simply to volition, i.e. purposive striving evidenced when one or more individuals decides on and commits to certain action.

2 This article's notion of existential humanness is intended to be fully compatible with Yalom's existential givens, including freedom, death, isolation, and meaning [45].
} 
person-situation interaction as a complex, interdependent function of mental and behavioral structures (i.e., states and traits) and processes. He did so as follows

$$
[P, S]=F\left[S t_{(T, S e)}, P C\right]_{(M, B)}
$$

Where $P$ equals "person", $S$ equals "situation", $S t$ equals "structure", $T$ equals "trait", $S e$ equals "state", $P c$ equals "process", $M$ equals "mind", and $B$ equals "behavior" [20]. (Traits and states are treated as distinct types of psychological structures.) $[P, S]$ is a whole composed entirely of parts $S t_{M S e}, S t_{B S e}, S t_{M T}, S t_{B T}, P c_{M}$, and $P c_{B}$, which respectively denote "mental states", "behavioral states", "mental traits", "behavioral traits", "mental processes", and "behavioral processes". Informally, (3) reads: person-situation interaction is a function of mental and behavioral structures ${ }^{5}$ and processes.

The more direct formalization of $P$ is now undertaken

$$
P=F[S l, O t]
$$

Where $S l$ equals "self” and $O t$ equals “other". Self has received a recent psychological treatment in Klein [7], where William James' classical notions of "self-as-known" and "self-as-knower" received updates to a more holarchic notion. Klein identifies two distinct kinds of selves from cognitive neuroscience and clinical case work involving memory and knowledge, in particular. Klein's epistemological self is "the self of neural instantiation: the neuro-cognitive categories of self-knowledge" (p. 20); his ontological self is "the self of first-person subjectivity...that consciously apprehends the content of the epistemological self" (p. 46). Klein's dualistic view of self may be characterized as holarchic-i.e., subjective-objective - to the extent that neurocognition is ontologically objective (in Searle's sense [8]) whereas first-person subjectivity (as discussed topically in, viz., [9]) is ontologically subjective. Dennett [17] also offered a novel theory of self, defining it as a center of narrative gravity, a "purely abstract object...[and] fiction". This treats self entirely as an ontologically subjective phenomenon.

Other is a concept that, while theoretically opposed from the notion of self, has received marginal attention from psychologists. The possibilities of the psychological study of other open numerous such constructs. Hyphenated constructs for the same study of self include: self-compassion, self-confidence, self-control, self-distancing, self-doubt, self-efficacy, selfexpansion, self-harm, self-reflection, self-suppression [44], self-determination, self-care, self-loathing, self-comparison, selfconcept, self-esteem, self-handicapping, self-image, self-perception, self-regulation, self-reference ([40], p. 253), selfactualization [41], self-transcendence, self-knowledge, self-ignorance ([39], p. 713), self-interest, self-report, self-replication (as denoted by "autopoiesis" - see [43] for a discussion of autopoietic technologies), self-directed, self-talk, self-reliance, selfrealization, self-defeating, self-concept, self-identify, self-as-known, self-as-knower, self-sabotage, self-aggrandizement, selfeffacement, self-evident, self-love, and self-consciousness. Thus, potential constructs for the human study of other include: othercompassion, other-confidence, other-control, other-distancing, other-doubt, other-efficacy, other-expansion, other-harm, otherreflection, other-suppression, other-determination, other-care, other-loathing, other-comparison, other-concept, other-esteem, other-handicapping, other-image, other-perception, other-regulation, other-reference, other-actualization, other-transcendence, other-knowledge, other-ignorance, other-interest ${ }^{6}$, other-report ([2], p. 352), other-replication, other-directed, other-talk, otherreliance, other-realization, other-defeating, other-concept, other-identify, other-as-known, other-as-knower, other-sabotage, other-aggrandizement, other-effacement, other-evident, other-love, and other-consciousness. Further "other" concepts likely remain to be named.

In the context of augmented cognition, the central role of the self who thinks (i.e., from Descartes' original cogito) is easily imagined and difficult, if not impossible, to successfully refute. However, the notion of "other minds" continues to plague the analytic philosophy of mind, in particular (see the famous "problem of other minds" [14]). Resolving this problem, which consists in answering whether - and, if so, then how — we may come to know that other people's minds exist, would be tantamount to knowing how we could know of other people's cognitions (and affects and motivations, a la Sood's PlatonicFreudian formula of mind below). Such knowledge would be requisite for its instrumentalization; and, if technology consists in the instrumentalization of knowledge — not merely of information, which is truth value-neutral — then knowledge of other minds is requisite for any technology that would augment user cognition.

\footnotetext{
${ }^{3}$ All sufficiently similar equations offered hereon are syntactically consistently with Lewin's field theory of behavior [12] and Sood's enactive person-situation formula. Two-letter variable-naming is allowed to the extent that the same is in software program variable declaration, and is particularly necessary in cases of multiple constructs beginning with identical first letters.

${ }^{4}$ The kind of person-situation interaction expressed through (4) — which has been formalized to render the construct more applicable within mathematical, theoretical, and computational contexts-is thus distinctly psychological in accommodating mind and behavior. Mind, behavior, person, and situation comprise modern psychology's highest-level topics of study.

${ }^{5}$ Such mental and behavioral structures may be either traits, states, or hybrid "trates" (this appears to be a novel neologism). The use of trate over both state and trait would eliminate the need to use latter in formalisms such as (3).

${ }^{6}$ Other-interest has been covered by Gerbasi \& Prentice in their creation of the Self- and Other-Interest Inventory [42].
} 
Knowledge here is understood as a form of cognition represented in one's mind, or enacted procedurally via the skilled use of one's body. In either case, it is encoded in an "embodied", neurocognitive substrate. Representing knowledge via formal syntax and operations is the domain of mathematical logic, which also extends into computation primarily in the form of discrete logical operations determined by the programmer. ${ }^{7}$

\subsection{The Platonic-Freudian Model of Mind}

Sood [2] formalized $M$ mind as a portion of $\psi$, psychology (denoting the field of psychology, including its two most eminent and high-level, modern topics of study). He did so as follows

$$
\psi=F[M, B]
$$

Where $B$ equals behavior. Sood's formalism was disciplinary in nature; person-situation interaction (with $(M, B)$ operating as a subscript to $\left.\left[S t_{(T, S e)}, P c\right]\right)$ could just as easily have been set equal to $\psi$. In any case, $M$ was next formalized as follows

$$
\left.M=F\left[(A, C, M v)_{(U-,} S b-\right) C s\right]
$$

Where $A$ equals "affect", $C$ equals "cognition", $M v$ equals "motivation", $U-$ equals "un-", $S b-$ equals "sub-", and $C s$ equals "consciousness". According to the right portion of (6)'s subscript, each of these elementary mental phenomena may be either unconscious, subconscious, or conscious. (8) yields the following nine constructs: "unconscious affect", "subconscious affect", and "conscious affect"; "unconscious cognition", "subconscious cognition", and "conscious cognition"; and "unconscious motivation", "subconscious motivation", and "conscious motivation". Any of these constructs could informally be considered subminds in a manner analogous to how each of the five-factor model's traits (Openness, Conscientiousness, Extraversion, Agreeableness, and Neuroticism) could be regarded as subpersonalities of a given person's overall personality.

The fusion of (2), (3), and (6) is now undertaken

$$
\left.[P, S]=F\left[S t_{(T, S e)}, P c\right]_{\left[(A, C, M v, B)_{(U-, ~ S b-) C s}\right.}\right]
$$

(7) reads: Person-situation interaction is a function of unconscious, subconscious, and conscious affective, cognitive, motivational, and behavioral traits, states, and processes. B here was not part of Sood's original Platonic-Freudian model of mind, nor does (7) need to imply that it now is. It has been added to (7) (and subsequent invocations of $F\left[S t_{(T, S e)}, P c\right] .$. ) given its historical closeness with $M V$ (see the conation concept, as in Plato's work [37]), and to accommodate Maslow's view of behavior almost always requiring motivation in order to occur.

The tripart primitives listed in Table 1 follow from the compound psychological primitives named between (6) and (7), and in (7)

Table 1. Tripart primitives of Sood's Platonic-Freudian model of mind 9

\begin{tabular}{|c|c|}
\hline $\begin{array}{c}\text { Structures } \\
\text { and } \\
\text { Processes }\end{array}$ & Freudian topography \\
\hline
\end{tabular}

\footnotetext{
${ }^{7}$ See [15] for a critique of the embodied view of knowledge, and [16] for a systematic illustration of the (computational) cognitivist approach to it.

${ }^{8}$ Formula (6) drew from Freud's topographical model of mind [18] on one hand - where mental content passes between the unconscious and conscious sub-minds via the intermediary subconscious - and Revelle's recent attempt to synthesize Plato's tripartite model of mind (consisting of precursors for affect, cognition, and motivation) into a formal personality framework [19].

${ }^{9}$ References to constructs of the five-factor model of personality (a.k.a. the "Big Five") are derived from [35].
} 


\begin{tabular}{|c|c|c|c|}
\hline & $\begin{array}{c}\text { CsASe: } \\
\text { Conscious } \\
\text { affective state } \\
\text { (e.g., palpable } \\
\text { moods; feelings } \\
\text { "of the moment") }\end{array}$ & $\begin{array}{l}\text { CsMvSe: } \\
\text { Conscious } \\
\text { motivational state } \\
\text { (e.g., a mode of } \\
\text { realization enabling } \\
\text { one to reach a goal } \\
\text { state or overcome a } \\
\text { given situation) }\end{array}$ & $\begin{array}{c}\text { CsCT: } \\
\text { Conscious cognitive } \\
\text { trait } \\
\text { (e.g., "woke"10 } \\
\text { Openness) }\end{array}$ \\
\hline \multirow{5}{*}{$\begin{array}{l}\text { Platonic } \\
\text { triad } \\
\text { (including } \\
M v \text { instead } \\
\text { of } B \text { ) }\end{array}$} & $\begin{array}{c}\text { CSAT: } \\
\text { Conscious } \\
\text { affective trait } \\
\text { (e.g., woke } \\
\text { Neuroticism) }\end{array}$ & $\begin{array}{c}\text { CSMVT: } \\
\text { Conscious } \\
\text { motivational trait } \\
\text { (e.g., woke } \\
\text { Conscientiousness) }\end{array}$ & $\begin{array}{c}\text { CsCSe: } \\
\text { Conscious cognitive } \\
\text { state (e.g.: being } \\
\text { pensive; being } \\
\text { momentarily lost or } \\
\text { absorbed in thought, } \\
\text { i.e. introspective, } \\
\text { reflective, } \\
\text { ruminative, } \\
\text { imaginative, } \\
\text { cogitative; } \\
\text { daydreaming) }\end{array}$ \\
\hline & $\begin{array}{c}\text { SbCsCSe: } \\
\text { Subconscious } \\
\text { cognitive state } \\
\text { (e.g., REM- } \\
\text { dreaming) }\end{array}$ & $\begin{array}{c}\text { SbCsASe: } \\
\text { Subconscious } \\
\text { affective state } \\
\text { (half-awareness of } \\
\text { mood, fleeting } \\
\text { feelings or } \\
\text { emotionality) }\end{array}$ & $\begin{array}{c}\text { SbCsMvSe: } \\
\text { Subconscious } \\
\text { motivational state }\end{array}$ \\
\hline & $\begin{array}{c}\text { SbCsCT: } \\
\text { Subconscious } \\
\text { cognitive trait } \\
\text { (e.g., } \\
\text { Jungian/Myersian } \\
\text { "iNtuitive" type) }\end{array}$ & $\begin{array}{c}\text { SbCsAT: } \\
\text { Subconscious } \\
\text { affective trait (half- } \\
\text { awareness of } \\
\text { Neuroticism or } \\
\text { Extraversion - } \\
\text { Enthusiasm) }\end{array}$ & $\begin{array}{c}\text { SbCsMvT: } \\
\text { Subconscious } \\
\text { motivational trait }\end{array}$ \\
\hline & $\begin{array}{c}\text { UCSMVSe: } \\
\text { Unconscious } \\
\text { motivational state }\end{array}$ & $\begin{array}{c}\text { UCSASe: } \\
\text { Unconscious } \\
\text { affective state (e.g., } \\
\text { subject undergoing } \\
\text { intuitive processing) }\end{array}$ & $\begin{array}{c}\text { UCSCSe: } \\
\text { Unconscious } \\
\text { cognitive state (e.g., } \\
\text { subject undergoing } \\
\text { intuitive processing) }\end{array}$ \\
\hline & $\begin{array}{c}\text { UCSMvT: } \\
\text { Unconscious } \\
\text { motivational trait } \\
\text { (e.g., } \\
\text { Conscientiousness } \\
\text { - Industriousness) }\end{array}$ & $\begin{array}{c}U C S A T: \\
\text { Unconscious } \\
\text { affective trait }\end{array}$ & $\begin{array}{c}\text { UCSCT: } \\
\text { Unconscious } \\
\text { cognitive trait (e.g., } \\
\text { Openness - Intellect } \\
\text { or Imagination) }\end{array}$ \\
\hline
\end{tabular}

${ }^{10}$ Woke in this article "riffs" off of the cultural use of the term. Formally, it is a trate of being "subjectively self- and/or other-aware; perhaps, but not necessarily, as such awareness is of perceived slight or social injustice". 


\begin{tabular}{|c|c|c|}
\hline $\begin{array}{c}C S A P C \text { : } \\
\text { Conscious } \\
\text { affective process } \\
\text { (e.g., processing } \\
\text { of emotions during } \\
\text { appropriate } \\
\text { psychotherapeutic } \\
\text { intervention) }\end{array}$ & $\begin{array}{c}C S M v P c \text { : } \\
\text { Conscious } \\
\text { motivational process } \\
\text { (setting one's mind to } \\
\text { accomplish a goal or } \\
\text { complete a task) }\end{array}$ & $\begin{array}{c}C s C P: \\
\text { Conscious cognitive } \\
\text { process }\end{array}$ \\
\hline $\begin{array}{c}S b C s C P c: \\
\text { Subconscious } \\
\text { cognitive process }\end{array}$ & $\begin{array}{c}S b C s A P c: \\
\text { Subconscious } \\
\text { affective process }\end{array}$ & $\begin{array}{c}\text { SbCSMvPc: } \\
\text { Subconscious } \\
\text { motivational } \\
\text { process }\end{array}$ \\
\hline $\begin{array}{c}U C S M v P c \text {. } \\
\text { Unconscious } \\
\text { motivational } \\
\text { process }\end{array}$ & $\begin{array}{c}U C S A P C \text { : } \\
\text { Unconscious } \\
\text { affective process } \\
\text { (e.g., System } 1 \\
\text { intuition) }\end{array}$ & $\begin{array}{c}U C S C P C \text { : } \\
\text { Unconscious } \\
\text { cognitive process } \\
\text { (e.g., System } 1 \\
\text { intuition) }\end{array}$ \\
\hline
\end{tabular}

The mathematical-theoretic approach to psychology undertaken here and in [1,2] requires an expansion of Freudian topography. Specifically, if unconsciousness is zero (0) awareness; subconsciousness is half (0.5) awareness; and consciousness is full (1) awareness, then mathematically, one could speak equally of negative subconsciousness and consciousness: -0.5 and -1 awareness, respectively. Negative psychology is to be contrasted with positive psychology in that the former includes psychopathology and clinical and abnormal psychologies, whereas positive psychology's core topic of study is well-being.

Sood $[1,2]$ formalized the sub-primitives of Table 1's triads into his person-situation and mind formulae, but neglected to explicate them rigorously. Affect has been defined in [24] as "a non-conscious experience of intensity... a moment of unformed and unstructured potential". It "cannot be fully realized in language" and "is always prior to and/or outside of consciousness". It is "the body's way of preparing itself for action in a given circumstance by adding a quantitative dimension of intensity to the quality of an experience".

Starting with Kahneman and Tversky's pioneering work (laid out for a more mainstream audience in [25]), cognition in modern psychology has frequently been defined as consisting of Systems 1 and 2. In this "dual-process" theoretic model, System 1 consists of thought that is fast, instinctive, affective, and unconscious ${ }^{11}$. System 2, on the other hand, consists of slower, more deliberative, logical, and conscious cognition. ${ }^{12}$

Motivation has been defined differently by varying theorists. The basic question for the science of motivation is why beings (viz.: humans, animals, and/or robots) do what they do. Anthropological theories of motivation abound. In psychology, prominent such theories include drive-reduction, evolutionary, and optimal arousal theories. A parsimonious, complete theory of motivation would minimally need to answer the questions of why such beings want to, should, need to, and simply do carry out their behaviors.

Maslow developed the now-famous hierarchy of needs in which humans successively fulfill needs of varying classes [27]. He believed that motivations could be meaningfully separated into groups based on two criteria: 1) which of them must be acted upon first in order for a person to survive, and 2) which are necessary to act upon for attaining "self-actualization" (pp. 375-82). Maslow and Horney [36] considered self-actualization respectively as a syndrome and trait of neurotic personalities, reflecting the state of psychological theory during the mid- $20^{\text {th }}$ century as psychoanalytic and clinical more so than "positive" (i.e., being more interested in human growth and potential, flourishing, and well-being).

In decreasing order of their relative degrees of necessary fulfillment, Maslow's motivations were "physiological", "safety", "love", "esteem", and self-actualization needs. Still, the question of how motivations such as these interact-both with one another and with other factors (cognitive, emotional, behavioral) - has not yet been answered. For Maslow, motivation was almost always necessary for behavior; additionally, he believed that more than one motivation typically figures into a single

\footnotetext{
${ }^{11}$ Intuition is an unconscious process, but its outputs (occurring as insight, e.g. realized by a subject in an "aha!" moment) are conscious.

${ }^{12}$ See [26] for a further unpacking of this framing.
} 
behavior (p. 370). It would seem, therefore, that a Maslowian science of motivation would need to work first from behavior to motivation, and possibly only afterward toward other psychological phenomena (e.g., affect and cognition).

Maslow [27] stated that "any conscious desires (partial goals) are more or less important as they are more or less close to the basic needs [of Maslow's hierarchy]" (p. 384). If it is accepted that Maslow recognized some fundamental connection between desires and goals, then it would follow from an earlier statement he made-i.e., that "conscious, specific, local-cultural desires are not as fundamental in motivation theory as the more basic, unconscious goals" (p. 370) - then for Maslow, unconscious wants will always be closer to our basic needs than will conscious ones. ${ }^{13}$

Kelly [28] considered the following to be motivational concepts: "laziness", appetite, and affection (p. 77). Kelly understood motivations as being parts of greater systems of construction evidenced by individuals (e.g., through dialogue). Considered this way, motives can be thought to play out within close proximity to beliefs. However, "appetite" is closer to one of Maslow's basic needs, and is also something of a raw instinctual property characterizing a living being's consumptive capacity with respect to a suitable object $Y$ (e.g., food). Meanwhile, Kelly himself provided another, more historical framing of motivation in terms of the synonymous triads of "cognition, conation [emphasis added], and affection", "intellect, will [emphasis added], and emotion", and (in more modern terms) "thought, action [emphasis added], and feeling" (pp. 68-9). Motivation, then - to the extent that it is will manifest in one's action - may be determined as such in reverse fashion from behaviors. However, Maslow [27] asserted that "Motivation theory is not synonymous with behavior theory... While behavior is almost always motivated, it is almost always biologically, culturally, and situationally determined as well" (p. 371). ${ }^{14}$ Regarding the possibility of unmotivated behavior, Maslow stated that "expressive behavior is either unmotivated or...less motivated than coping behavior" ([38], p. 138).

Expressive behavior is unconscious ( $U C S B$ ) while coping behavior is conscious $(C s B)$.

States and traits could be viewed as being conditioned respectively by situations and persons. A more mathematical view may be taken, whereby states and traits are distinguishably measurable based on a psychological phenomena's duration or degree of stability vs. plasticity. It is presumed that states would be of lesser duration and greater stability, while traits are of greater duration and lesser plasticity.

\subsection{The $S$ Equation}

The psychological situation concept has been lamented by Rauthmann et al. [3] as being used often "haphazardly, ambiguously, [and] inconsistently" in the literature (p. 363). To ameliorate this, the authors proposed "three different basic kinds of situational information: cues (composition information), characteristics (psychological meaning information) and classes (category information)" (p. 363). Cues represent "physically present, scalable and (relatively) objectively quantifiable stimuli" (p. 364). Characteristics capture the "psychologically important meanings of perceived cues, thus summarizing a situation's psychological 'power" (p. 364). Finally, classes represent "abstract groups, or types, of situations" (p. 364).

The formalization of Rauthmann et al.'s situation framework is now undertaken

$$
S=F[C u, C h, C e]
$$

Where $S$ equals "situation", $C e$ equals "class", $C h$ equals "characteristic", and $C u$ equals "cue". Given (3), (4), and (8) and the transitive property, (9) results

$$
[P, S]=[F[S l, O t], F[C u, C h, C e]]
$$

By (9), person-situation interaction is extended as a function of the interaction between selves and others with cues, characteristics, and classes.

The following equation fuses (2)-(8), above

$$
\left.[F[S l, O t], F[C u, C h, C e]]=F\left[S t_{(T, S e)}, P C\right]_{\left[(A, C, M v, B)_{(U-, ~ S b-) C s}\right.}\right]
$$

(10) reads: Person-situation interaction as a function of self and other-cue, characteristic, and class interaction is a function of unconscious, subconscious, and conscious affective, cognitive, motivational, and behavioral traits, states, and processes.

\footnotetext{
${ }^{13}$ The theory that unconsciousness is "greater" in various respects (more influential motivationally, for the present context) than consciousness goes back to at least Freud; this theory may be more amenable to a truly scientific analysis today. Regardless, there remain the scientific questions associated with motivation's operationalization. Two such questions may be posed. First: How do we identify distinct motivations as such - both in terms of their relatively more autonomous properties, and their interactions in a person or persons' overall motivational system(s)? And second - how do motivations interact with other psychological phenomena like cognitions and emotions?

${ }^{14}$ How can Maslow's hierarchical view of motivation be compared with Kelly's more dynamic one? For Kelly, a more socially enactive and cognitive path would render motivation a clearer construct for psychological scientists (including personality psychologists) to operationalize.
} 


\section{$4 \quad$ Problem-Solving Utility of an Augmented Third-Force Framework}

Solving massive socio-technical problems requires an equally massive scientific framework, like Sood's holarchic psychoinformatics. But what is this? Sood defined psychoinformatics as an interdisciplinary space joining psychology with computer science. Sood defined holarchy as a subjective-objective ontology with holons serving as basic units denoting partwholes. Computer science is an objective domain, as is neurocognitive-behavioral psychology. Phenomenology, the study of human experience, is an ontologically subjective domain. Augmented cognition is a multi-ontological field depending on the mental paradigm employed by the researcher. Jackendoff's computational mind [20] is objective, but his phenomenological one is subjective. A holarchic approach to augmented cognition - or perhaps, more appropriately, augmented mind, if mind is granted to be broader than cognition - would mix both of these. From this view, and in keeping with this article's formalisms, augmented mind researchers would also need to consider augmented affect, behavior, and motivation in order to be holistically psychological.

Augmented cognition updated to holarchic, mental augmentation would be simultaneously and equally a field interested in neurocognition and phenomenology (i.e., neurophenomenology in Varela's [21] proposed sense). Such a field could contribute to solving problems like climate change that are commonly known to be associated with cognitive deficits like confirmation bias (e.g., as demonstrated by skeptics) by generating and focusing on novel, positive concepts. An example of one such construct is "confirmation neutrality", which — rather than denoting the phenomenon of seeking evidence to confirm one's beliefs (as in confirmation bias) — denotes the phenomenon of seeking evidence to support only one's true beliefs (e.g.: "the sun will rise tomorrow"). The elaboration and study of such a construct would lend itself well to the epistemological augmented cognition researcher who defines knowledge in general as justified true belief.

Another construct that would be of great utility to the positive ecopsychologist in particular is seasonal affective "superorder" (SAS), as opposed to the informal clinical category seasonal affective disorder (SAD). While psychological disorder refers to fragmented person-situation interaction (i.e., mental and behavioral states and/or traits per (3)), such superorder would refer instead to integrated $[P, S]=F\left[S t_{(T, S e)}, P c\right]_{(M, B)}$. Theoretically necessary constructs for informal psychology that follow from SAD include "seasonal cognitive disorder" (SCD), "seasonal motivational disorder" (SMD), and "seasonal behavioral disorder" (SBD). For positive psychology, "seasonal cognitive superorder" (SCS), "seasonal motivational superorder" (SMS), and "seasonal behavioral superorder" (SBS) would follow from SAS.

"Superpersonality" and super-mind follow from Section 3.3's consideration of subpersonality and sub-mind, respectively. Taking these constructs further, one could also speak (however tentatively) of "superbehavior" (following from the existent subbehavior); superconsciousness; "subperson" and "superperson"; "subsituation" and "supersituation"; "subaffect" and "superaffect"; "supercognition" (particularly relevant for augmented cognition, and following from the existent subcognition); "submotivation" and "supermotivation"; and "subother" and "superother" (following from the existent subself and superself). The constructs encapsulated here by quotation marks remain to be elaborated philosophically, theoretically, scientifically, and practically.

"Cogfection" refers to affective cognition. Cogfection is relevant to the proposed System 3 type of thought, which is subconscious and both cognitive and affective [48]. In the psychological literature, intuition has generally been asserted as being affective and cognitive. However, recent discussions of System or Type [49] 3 thought vex this decision. If Type 3 is an average of System 1 and 2 processes - where System 1 consists of unconscious affect and system 2 consists of conscious cognition-then Type 3 thought stands as subconscious cogfect.

"Playing memory" (PM) should serve as a contrast construct to working memory. Working memory (WM) stores memory for more time than short-term memory (STM) does, but less than long-term memory (LTM). Thus, WM may be viewed as existing between STM and LTM in terms of storage duration; however, LTM's duration of storage ( $\sim 90 \mathrm{~s})$ is much closer to STM's ( 30 s) than LTM's (potentially forever). Regardless, memory in general has received a sprawling treatment compared with its opposing (yet, cognitively- and neurologically-related - see [50]) construct foresight. Rather than storing previously encountered content like memory does, foresight projects future content. If WM serves as our support system for completing cognitive work, then PM should do the same with respect to affective play (though it might not serve such so much as accompany it freely). Adding foresight to the present discussion portends the additions of the following constructs: "short-term foresight" (STF), "working foresight" (WF), "long-term foresight" (LTF), and "playing foresight" (PF).

Lastly, the construct "wholicle" (pronounced whole-ical) is necessary for holarchic theory in general. Wholicles are to be contrasted with particles, and are intended to accompany the latter and follow from its role in the definition of holons as partwholes [2]. In terms of current physics, wholicles refer to a level immediately above the macroscopic particle-i.e., the "microscopic wholicle" (all the way up to "macroscopic wholicle"). Macroscopic particles include powder, dust, stand, car parts, and galactic stars; microscopic wholicles refer to entities at least as large as galaxies. Such a term is more readily explicable in 
terms of current physics, but it is speculated that wholicles should refer more broadly and analogously to large entities within any holarchic domain. Within psychology, a wholicle might refer to the set of entities greater than persons or situations. Thus, the whole that is person-situation interaction represents the best starting point for such an advancement in holarchic-psychological theory.

\section{Conclusion}

Boden [32] explicated the evolution of theoretical psychology from the computational perspective (both cornerstones to the approach undertaken in this article and elsewhere [1,2]) a la David Marr's work:

"Marr argued that an adequate psychology will comprise explanations at three distinct but interrelated levels: computational, algorithmic, and hardware... This approach to theoretical psychology evolved through the late 1970s.

"The computational level...provides an abstract formulation of the information-processing task which defines a given psychological ability, together with a specification of the basic computational constraints involved. Where vision is concerned, these constraints are grounded in the structure of the physical world...they provide the necessary and sufficient computational basis for any creature (man, monkey, Martian—or machine) faced with the task in question.

"The second, algorithmic, level takes account of these constraints in specifying the psychological processes, or computations, by means of which the task is actually performed, which may differ in men and Martians. These processes are defined in terms of a particular system of representation, which can be proved to be reliable (to yield the relevant information) by reference to the top-level constraints" (pp. 49-50).

Marr's approach was similar to this article's in that both deem the informatic approach to theoretical psychology as necessary. The present article maintains skepticism regarding whether this approach is sufficient, though, particularly if phenomenological psychology is to be incorporated into a complete, holarchic psychology. ${ }^{15}$

Boden also detailed Marr's methodology, which included hardware:

"The hardware-level deals with the neural mechanisms that embody the computational and algorithmic functions specified at the other two levels, showing how their psychological properties and anatomical connectivities enable them to do so. Hardware-properties may vary between species even more than algorithmic ones do, and are very different in machines.

"Marr's methodology was centered on computational, top-level, understanding of the nature of the informationprocessing task being modelled. He insisted that only if psychology is grounded in such understanding can be it a systematic science, as opposed to a ragbag of empirical findings, theoretically unjustified hunches, and $a d$ hoc assumptions introduced to compensate for inadequacies in so-called theory" (p. 51).

Marr's informational-theoretic psychology thus included three levels: "computational", algorithmic, and hardware. It may be viewed as a predecessor to modern psychoinformatics, which has been discussed in numerous works [e.g., 1, 2]. A more complete psychology will someday successfully integrate phenomenological and computational psychologies. As Smith \& Hamid [34] claim: "substantial improvement in AI could be achieved by adopting a hybrid framework in which embodied cognition...may contain representational abstract, and symbolic aspects" (p. 67). As these authors note, the potential for humanmachine coexistence is strong.

\section{References}

1. Sood, S. (2020) The Psychoinformatic Complexity of Humanness and Person-Situation Interaction. In: Arai K., Bhatia R. (eds) Advances in Information and Communication. FICC 2019. Lecture Notes in Networks and Systems, vol 69. Springer, Cham

2. Sood S. et al. (2019) Holarchic Psychoinformatics: A Mathematical Ontology for General and Psychological Realities. In: Schmorrow D., Fidopiastis C. (eds) Augmented Cognition. HCII 2019. Lecture Notes in Artificial Intelligence, vol 11580. Springer, Cham

3. Rauthmann, J., Sherman, R., Funder, D.: Principles of situation research: Towards a better understanding of psychological situations. Eur. J. Pers. 29, 363-381 (2015).

4. Zahavi, D: Self and Other: Exploring Subjectivity, Empathy, and Shame. Oxford University Press, Oxford (2014)

\footnotetext{
${ }^{15}$ For the most famous and sprawling challenge to a purely computational approach to psychology, see [33].
} 
5. Buber, M.: I and Thou. (1958)

6. Henriques G.: A New Unified Theory of Psychology. Springer, New York (2011). https:// doi.org/10.1007/978-14614-0058-5

7. Klein, S.: The Two Selves: Their Metaphysical Commitments and Functional Independence. Oxford University Press, Oxford (2014)

8. Searle, J.: The Mystery of Consciousness. New York Review Books, New York (1997)

9. Varela, F. \& Shear, J.: The View from Within: First-Person Approaches to the Study of Consciousness. Imprint Academic, Thorverton (1999)

10. Cornelius, R.: The Science of Emotion: Research and Tradition in the Psychology of Emotion. Prentice-Hall, Upper Saddle River (1996)

11. Varela, F., Thompson, E., \& Rosch, E.: The Embodied Mind: Cognitive Science and Human Experience. The MIT Press, Cambridge (2000)

12. Lewin, K.: Field theory and experiment in social psychology: Concept and methods. Am. J. Soc. 44, 868-896 (1939)

13. Skinner, B.F.: Generic nature of the concepts of stimulus and response. J. Gen. Psychol. 12, 1240-1265 (1935)

14. Solipsism and the Problem of Other Minds. https://www.iep.utm.edu/solipsis/. Accessed 12 Nov 2019

15. Hovhannisyan G., Henson A., Sood S. (2019) Enacting Virtual Reality: The Philosophy and Cognitive Science of Optimal Virtual Experience. In: Schmorrow D., Fidopiastis C. (eds) Augmented Cognition. HCII 2019. Lecture Notes in Computer Science, vol 11580. Springer, Cham

16. Hancock M., Stiers J., Higgins T., Swarr F., Shrider M., Sood S. (2019) A Hierarchical Characterization of Knowledge for Cognition. In: Schmorrow D., Fidopiastis C. (eds) Augmented Cognition. HCII 2019. Lecture Notes in Computer Science, vol 11580. Springer, Cham

17. Dennett, D. C.: The self as a center of narrative gravity. In: F. Kessel, P. Cole, \& D. Johnson (eds.) Self and Consciousness: Multiple Perspectives. Erlbaum, Hillsdale (1992)

18. Freud, S.: The Interpretation of Dreams. (J. Strachey, Trans.) Basic Books, New York (1955). (Original Work Published in 1899)

19. Revelle, W.: Integrating personality, cognition, and emotion: Putting the dots together? (2011). https://www.personality-project.org/revelle/publications/BPSP-revelle.pdf. Accessed 9 Jan 2019

20. Jackendoff, R.: Consciousness and the Computational Mind. The MIT Press, Cambridge (1987)

21. Varela, F.: Neurophenomenology as a methodological remedy to the hard problem. J. Consciousness Stud. 3(4), 330-349 (1996).

22. McCrae, R., Costa, P.: Validation of the five-factor model of personality across instruments and observers. J. Pers. Soc. Psychol. 51(1), 81-90 (1987)

23. Pervin, L.: Personality. In: Kazdin, A. (ed.). Encyclopedia of psychology, vol. 6, pp. 100-106. American Psychological Association: Washington, DC (2000)

24. Shouse, E.: Feeling, emotion, affect. M/C J. 8(6) (2005). http://journal.media-culture.org.au/0512/03-shouse.php. Accessed 18 Nov 2019

25. Kahneman, D.: Thinking, Fast and Slow. Farrar, Straus and Giroux [Kindle DX version] (2011)

26. Gore, J., Sadler-Smith, E.: Unpacking intuition: A process and outcome framework. Rev. Gen. Psychol. 15(4), 304-316 (2011)

27. Maslow, A. H.: A theory of human motivation. Psychol. Rev. 50, 370-96 (1943)

28. Kelly, G.: Clinical Psychology and Personality: The Selected Papers of George Kelly. John Wiley \& Sons, Inc., New York (1969).

29. Dweck, C., Leggett, E.: A social-cognitive approach to motivation and personality. Psychol. Rev. 95(2), 256-273 (1988).

30. Proctor, C., Tweed, R., Morris, D.: The Rogerian fully functioning person: A positive psychology perspective. J. Humanist. Psychol. 56(5), 1-28 (2015).

31. Horley, J.: The units of analysis problem in psychology: An examination and proposed reconciliation. In: Baker W.J., Mos L.P., Rappard H.V., Stam H.J. (eds.) Recent Trends in Theoretical Psychology. Recent Research in Psychology. Springer, New York (1989).

32. Boden, M. A.: Computer Models of Mind. Cambridge University Press, Cambridge (1984).

33. Dreyfus, H. L.: What Computers Still Can't Do: A Critique of Artificial Reason. [Kindle DX version] (1999)

34. Smith, N. L., Hamid, O. H.: Embodied cognition and human-machine coexistence. UKH J. Sci. Eng. 1(1), 67-71 (2017).

35. DeYoung, C. G., Weisberg, Y. J., Quilty, L. C., Peterson, J. B.: Unifying the aspects of the Big Five, the interpersonal circumplex, and trait affiliation. J. Pers. 81(5), 465-75 (2013).

36. Horney, K.: Neurosis and Human Growth: The Struggle Toward Self-Realization. W. W. Norton \& Company, New York (1991). (Original Work Published in 1950)

37. Plato: The Republic. ( $2^{\text {nd }}$ ed.). Penguin Books, London (2007). (Original Work Published in $~ 375$ B.C.)

38. Maslow, A. H.: Toward a Psychology of Being. ( $1^{\text {st }}$ ed.). Wilder Publications, Blacksburg (2011). (Original Work Published in 1962)

39. Hofstadter, D.: Gödel, Escher, Bach: An Eternal Golden Braid (20 $0^{\text {th }}$ Anniversary ed.). Basic Books, New York (1999). 
40. Klein, S.: The self and science: Is it time for a new approach to the study of human experience? Curr. Dir. Psychol. Sci. 21(4), 253-57 (2012).

41. Maslow, A. H.: Motivation and Personality. Harper \& Row Publishers, New York (1954).

42. Gerbasi, M. E., Prentice, D. A.: The Self- and Other-Interest Inventory. J. Pers. Soc. Psychol. 105(3), 495-514 (2013).

43. Rabani, E., Perg, L. (2019) Demonstrably Safe Self-replicating Manufacturing Systems: Banishing the Halting ProblemOrganizational and Finite State Machine Control Paradigms. In: Schmorrow D., Fidopiastis C. (eds) Augmented Cognition. HCII 2019. Lecture Notes in Computer Science, vol 11580. Springer, Cham

44. McGonigal, J.: SuperBetter: A Revolutionary Approach to Getting Stronger, Happier, Braver, and More Resilient. Penguin Press, New York (2015).

45. Yalom, I. D.: The Gift of Therapy: An Open Letter to a New Generation of Therapists and Their Patients. Harper Perennial, New York (2002).

46. DARK STAR (1974). http://www.cinemah.com/altri/war/carpent.htm. Accessed 13 Jan 2020

47. Kukla, A.: Personality Theory: A Book of Readings. Canadian Scholars' Press, Toronto (1996).

48. Slingerland, E.: Trying Not to Try: The Art and Science of Spontaneity. Crown Publishers, New York (2014).

49. Dijksterhuis, A. \& Strick, M.: A case for thinking without consciousness. Per. Psychol. Sci. 11(1), 117-132 (2015). https://www.researchgate.net/publication/292188707_A_Case_for_Thinking_Without_Consciousness. Accessed 15 Jan 2020

50. Suddendorf, T.: Episodic memory versus episodic foresight: similarities and differences. WIREs Cog. Sci. 1, 99-107 (2010).

51. Bandura, A. \& Huston, A. C.: Identification as a process of incidental learning. J. Abnorm. Soc. Psych. 63(2), 311-318 (1961). 